\title{
The Neurology of Memory: Quantitative Assessment of Retrograde Amnesia in Two Groups of Amnesic Patients
}

\author{
L. R. Squire, F. Haist, ${ }^{a}$ and A. P. Shimamura \\ Veterans Administration Medical Center and Department of Psychiatry, University of California, San Diego, La Jolla, \\ California 92093
}

The phenomenon of retrograde amnesia has important implications for understanding normal memory as well as its neural organization. Using 6 tests of remote memory, we evaluated the extent and severity of retrograde amnesia in 2 groups of amnesic patients -7 patients with alcoholic Korsakoff's syndrome and 5 other patients with amnesia (anoxia or ischemia, $N=3$; thalamic infarction, $N=1$; unknown etiology, $N=1$ ). Although there were individual differences, Experiment 1 showed that the severity and extent of retrograde amnesia was similar for the $\mathbf{2}$ groups. Retrograde amnesia was temporally graded across a period of about 15 years and was not detectable in more remote time periods. In Experiment 2, repeated testing during a 3 year period showed that amnesic patients and control subjects were similarly consistent in their responses. Amnesic patients did not catch up to control subjects by eventually accumulating as many correct answers as the control subjects. In Experiment 3, amnesic patients performed normally on a test of very difficult general information questions, which were based on material likely to have been learned long ago. In all 3 experiments, the 2 groups of amnesic patients performed similarly. The results support the following conclusions: (1) Extensive, temporally graded retrograde amnesia, which has been observed frequently in patients with Korsakoff's syndrome, occurs readily in other amnesic patients as well, even when their memory impairment appears well circumscribed; (2) patients with presumed damage to either the medial temporal or the diencephalic brain structures linked to memory functions can produce a similar kind of retrograde amnesia; (3) the impairment reflects a loss of usable knowledge, not simply difficulty accessing an intact memory store that can then be overcome given sufficient retrieval opportunities; (4) very remote memory, at least for factual information, can be intact in amnesia; (5) the structures damaged in amnesia support memory storage, retrieval, or both during a lengthy period of reorganization, after which representations in memory can become independent of these structures.

\footnotetext{
Received Apr. 20, 1988; revised July 21, 1988; accepted July 25, 1988.

I his research was supported by the Medical Research Service of the Veterans Administration, National Institute of Mental Health Grant MH24600, and the Office of Naval Research. We thank Joyce Zouzounis, Kim Rivero-Frink, Loni Shutler, Patty Vitale, and Scott Frank for research assistance.

Correspondence should be addressed to Larry R. Squire, Ph.D., VA Medical Center, V-116-A, 3350 La Jolla Village Drive, San Diego, CA 92161.

a Also at the Department of Psychology, San Dicgo State University, San Dicgo, California.
}

Copyright (C) 1989 Society for Neuroscience $0270-6474 / 89 / 030828-12 \$ 02.00 / 0$
Studies of human amnesia have provided useful information about the organization and neurological foundations of memory (Baddeley, 1982; Hirst, 1982; Cermak, 1982; Schacter, 1985; Squire, 1986; Weiskrantz, 1987). In amnesia, memory impairment can occur despite normal scores on conventional intelligence tests, normal immediate (digit span) memory, as well as intact language and social skills. The hallmark of the amnesic disorder is anterograde amnesia: an impaired ability to acquire information about new facts and episodes. In addition, patients exhibit retrograde amnesia: difficulty remembering information that was acquired prior to the onset of amnesia.

It has been widely acknowledged that the status of retrograde amnesia has important implications for understanding both the organization of normal memory as well as the function of the damaged brain structures. Unfortunately, the study of retrograde amnesia is made difficult by considerable methodological problems (Squire, 1974; Albert et al., 1979; Squire and Cohen, 1982), and published accounts of the phenomenon are strikingly diverse. Retrograde amnesia has variously been reported to be temporally graded and limited, affecting only the few years prior to the onset of amnesia (Milner et al., 1968; Squire et al., 1975); extensive and ungraded, i.e., affecting all the decades of adult life to a similar degree (Sanders and Warrington, 1971; Cermak and O'Connor, 1983; Damasio et al., 1985); or both extensive and temporally graded, i.e., affecting more than a decade prior to the onset of amnesia but in such a fashion that remote time periods are affected less than recent time periods (Albert et al., 1979; Meudell et al., 1980; Cohen and Squire, 1981; Beatty et al., 1987; Salmon et al., 1988). In the latter case, when retrograde amnesia was both extensive and temporally graded, memory for very remote events sometimes reached normal levels (Beatty et al., 1987; Salmon et al., 1988) and sometimes did not (Albert et al., 1979; Meudell et al., 1980; Cohen and Squire, 1981).

The present study evaluated retrograde amnesia by testing 2 different groups: 7 patients with Korsakoff's syndrome and 5 other patients who became amnesic as the result of an acute event. Korsakoff's syndrome has an insidious onset that makes it difficult to separate precisely anterograde from retrograde memory impairment. The 5 non-Korsakoff patients who participated in the present study became amnesic on a known date, so that it was possible in this group to identify unambiguously where retrograde amnesia began. These 2 patient groups and 2 groups of control subjects participated in 3 experiments. In the first experiment, subjects took 4 remote memory tests: recall and recognition of past public events (1950-1985) and recall and recognition of famous faces (1940-1985). The tests were updated versions of ones used in a previous study of retrograde amnesia (Cohen and Squire, 1981). 
In the second experiment, we considered the consistency of remote memory performance. A previous single-case study of remote memory (patient S.S., Cermak and O'Conner, 1983) showed by repeated testing that items answered incorrectly on one occasion could sometimes be answered correctly on a second occasion. This finding raised the possibility that amnesic patients might know much more about remote events than they can reveal on a single test. We evaluated the consistency of remote memory performance by testing amnesic patients and control subjects on a second occasion about a year after the first experiment. We then determined the consistency of each subject's performance across individual test items. Finally, 4 of the amnesic patients were tested on a total of 6 different occasions, and their cumulative performance across the tests was compared with that of control subjects.

In the third experiment, we evaluated remote memory performance across different levels of test item difficulty. Items on remote memory tests often ask about relatively well-known, frequently encountered facts and events. Accordingly, a problem of interpretation arises when amnesic patients perform better on items about very remote events than on items about recent events. One possibility is that remote memory is intact relative to more recent memory. Thus, memory gradually becomes invulnerable to amnesia as time passes after learning. Another possibility is that remote memory has no special status. Items that ask about very remote events may primarily test strong and enduring memories, which are abundant in remote time periods; and items that ask about recent events may test weaker and more short-lived memories, which are abundant in recent time periods. To obtain a fairer test of very remote memory, we prepared a test of general information questions that were graded in difficulty. If amnesic patients could perform well even on very difficult remote memory questions, the evidence would be much stronger that their remote memory is intact. All of the test items asked about information available prior to 1930 , and one-fourth of the items could be answered by fewer than $10 \%$ of normal subjects.

\section{Experiment 1}

\section{Methods}

\section{Subjects}

Patients with Korsakoff's syndrome. Five men and 2 women with alcoholic Korsakoff's syndrome were tested. Six of these patients, K1K6, have been studied in this laboratory for several years, and their memory impairment is well documented (Squire and Shimamura, 1986). Remote memory performance was previously reported for 4 of the patients; K1, K3, K4, K5 (Cohen and Squire, 1981).

The 7 patients averaged 54.9 years of age at the beginning of the study. They had an average of 11.4 years of education and a mean Wechsler Adult Intelligence Scale-Revised (WAIS-R) IQ of 97.1. Individual IQ scores and Wechsler Memory Scale-Revised (WMS-R) index scores are shown in Table 1. Each of the 5 indices for the WMS-R yields a mean score of 100 in the normal population with a SD of 15 (Wechsler, 1987; see Butters et al., 1988, for a validation study of the WMS-R). Immediate and delayed (12 min) recall of a short prose passage averaged 5.0 and 0 segments, respectively ( 21 segments total). Copy and delayed (12 min) recall of the Rey-Osterrieth Complex Figure (Osterrieth, 1944; Lezak 1983) averaged 26.4 and 3.1 points, respectively (36 points total). Memory for 10 noun pairs (paired associate test) on each of 3 successive trials averaged $0.4,0.1$, and 1.3 word pairs. Free recall of 15 words (Rey auditory verbal learning test: Rey, 1964; Lezak, 1983) averaged 3.0,3.9, 4.4, 4.1, and 4.6 across 5 successive study/test trials. Recognition of 15 previously presented words and 15 new words presented one at a time, with instructions to make a yes/no choice, averaged $20.1,24.4,24.1,25.4$, and 26.4 correct responses across 5 successive study/test trials. The mean score on the Dementia Rating
Table 1. Description of amnesic patients

\begin{tabular}{|c|c|c|c|c|c|c|c|}
\hline \multirow[b]{2}{*}{$\begin{array}{l}\mathrm{Pa}- \\
\text { tient }\end{array}$} & \multirow[b]{2}{*}{$\begin{array}{l}\text { Age } \\
\text { (yr) }\end{array}$} & \multirow[b]{2}{*}{ WAIS-R } & \multicolumn{5}{|l|}{ WMS-R } \\
\hline & & & $\begin{array}{l}\text { Atten- } \\
\text { tion/con- } \\
\text { centra- } \\
\text { tion }\end{array}$ & Verbal & Visual & $\begin{array}{l}\text { Gen- } \\
\text { eral }^{a}\end{array}$ & Delay $^{a}$ \\
\hline \multicolumn{8}{|l|}{ KOR } \\
\hline K 1 & 42 & 90 & 62 & 80 & 60 & 69 & $<50$ \\
\hline K 2 & 66 & 103 & 101 & 78 & 72 & 72 & 66 \\
\hline K 3 & 48 & 88 & 80 & 77 & 83 & 75 & 57 \\
\hline $\mathrm{K} 4$ & 51 & 101 & 92 & 55 & 64 & $<50$ & 51 \\
\hline K 5 & 58 & 94 & 81 & 77 & 73 & 67 & 53 \\
\hline K 6 & 49 & 98 & 104 & 65 & 70 & 57 & 57 \\
\hline K 7 & 70 & 106 & 111 & 62 & 104 & 73 & 63 \\
\hline Mean & 54.9 & 97.1 & 90.1 & 70.6 & 75.1 & 65.0 & 56.7 \\
\hline \multicolumn{8}{|l|}{ AMN } \\
\hline $\mathrm{AB}$ & 47 & 119 & 87 & 62 & 72 & 54 & $<50$ \\
\hline GD & 45 & 92 & 109 & 86 & 88 & 85 & 60 \\
\hline LM & 55 & 111 & 132 & 87 & 96 & 90 & 65 \\
\hline WH & 64 & 113 & 88 & 72 & 82 & 67 & $<50$ \\
\hline MG & 55 & 111 & 111 & 82 & 68 & 69 & 50 \\
\hline Mean & 53.2 & 109.2 & 105.4 & 77.8 & 81.2 & 73.0 & 55.0 \\
\hline
\end{tabular}

"The WMS-R does not provide numerical scores for subjects who score below 50. Therefore, values below 50 were scored as 50 for computing group means. Abbreviations: KOR, patients with Korsakoff's syndrome; AMN, other amnesic patients; WAIS-R, Wechsler Adult Intelligence Scale-Revised Full Scale IQ; WMS$\mathrm{R}$, Wechsler Memory Scale-Revised.

Scale (Mattis, 1976) was 129.4 points out of a possible 144 points (range, 119-141). Most of the points were lost on the initiation-perseveration ( 4.4 points) and memory ( 7.0 points) subportions of the test. Additional neuropsychological data for these patients, as well as scores for control subjects on the tests just mentioned, can be found in Squire and Shimamura (1986).

Other patients with amnesia. Four men and 1 woman were tested. $\mathrm{AB}$ became amnesic in 1976 following an anoxic episode during a cardiac arrest; GD became amnesic in 1983 following a period of hypotension that occurred during major surgery; LM became amnesic in 1984 as the result of a respiratory arrest that occurred during an epileptic seizure; WH became amnesic in 1986, but without a known precipitating event. Preliminary magnetic resonance (MR) scans have identified bilateral medial temporal pathology. His amnesia appeared within a period of a few days at most, without known head trauma, seizure, or unconsciousness. MG became amnesic in 1986 following a bilateral thalamic infarction. Documentation of the memory impairment for 3 of these patients, AB, GD, and LM, has been presented previously (Squire and Shimamura, 1986). Remote memory performance for 2 of these patients (LM and WH) was reported in 2 recent single-case studies (Beatty et al., 1987; Salmon et al., 1988).

As a group, these 5 patients averaged 53.4 years of age at the beginning of the study. They had an average of 15.6 years of education and a mean WAIS-R IQ of 109.2. Individual IQ scores and WMS-R index scores are shown in Table 1 . Immediate and delayed $(12 \mathrm{~min})$ recall of a short prose passage averaged 6.0 and 0 segments, respectively. Copy and delayed ( $12 \mathrm{~min}$ ) recall of the Rey-Osterrieth Complex Figure averaged 28.8 and 4.5 points, respectively. Memory for 10 noun pairs on each of 3 successive trials averaged $0.8,0.6$, and 1.8 correct word pairs. Free recall of 15 words averaged $4.6,6.6,6.4,6.8$, and 6.4 across 5 successive study/test trials. Recognition of 15 previously presented words and 15 new words with a yes/no choice averaged $24.2,24.6,25.6,25.8$, and 27.4 correct responses across 5 successive study/test trials. The mean score on the Dementia Rating Scale was 135.6 points (range, 130-143), with most of the points lost on the memory subportion of the test $(6.2$ points).

Alcoholic control subjects. Nine alcoholic subjects, 6 men and 3 women, were tested and served as a control group for the patients with 


\section{PUBLIC EVENTS}
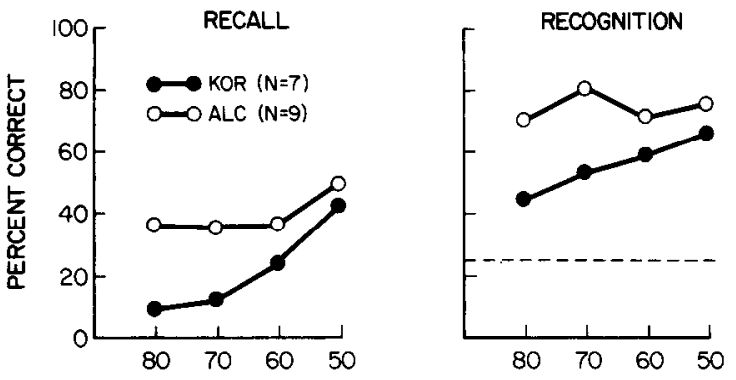

FAMOUS FACES
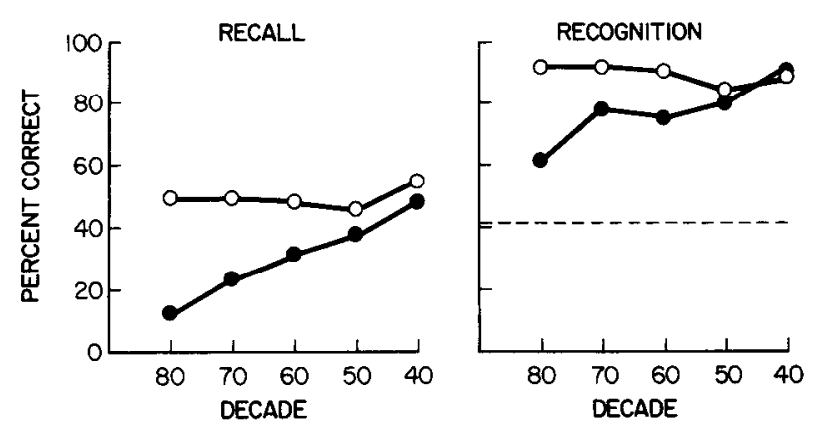

Figure 1. Performance of patients with Korsakoff's syndrome and alcoholic control subjects on the public events test (recall and recognition) and on the famous faces test (recall and recognition). Dashed lines indicate chance performance levels (public events $=25 \%$; famous faces $=41.5 \%$ ).

Korsakoff's syndrome. All subjects were current or former participants in alcohol treatment programs in San Diego County. None reported a history of cirrhosis or severe head injury (specifically, a period of unconsciousness lasting longer than $5 \mathrm{~min}$ ). The subjects reported an average drinking history of 11.7 years (range, 2-33 years) and had abstained from alcohol for an average of 2.4 years (range, 2-82 months) prior to participating in the study. These subjects averaged 51.0 years of age at the beginning of the study, had 12.7 years of education, and obtained average WAIS-R subtest scores of 19.2 for Information (18.0 for the patients with Korsakoff's syndrome) and $\mathbf{4 3 . 3}$ for Vocabulary (49.0 for the patients with Korsakoff's syndrome). Immediate and delayed $(12 \mathrm{~min})$ recall of a short prose passage averaged 7.6 and 5.5 scgments, respcctivcly.

Healthy control subjects. Eight healthy control subjects, 3 men and 5 women, were tested and served as a control group for the non-Korsakoff amnesic patients. All were employees or volunteers at the San Diego Veterans Administration Medical Center. They averaged 48.6 years of age at the beginning of the study, had 14.6 years of education, and obtained WAIS-R subtest scores of 22.5 for Information (22.0 for the patients) and 52.8 for Vocabulary (57.8 for the patients). Immediate and delayed $(12 \mathrm{~min})$ recall of a short prose passage averaged 7.3 and 6.9 segments, respectively.

\section{Tests}

Public events (recall and recognition). The test consisted of 92 questions about public events that had occurred from 1950 through $1985(1950 \mathrm{~s}$, $N=18 ; 1960$ s, $N=24 ; 1970$ s, $N=20 ; 1980$ s, $N=30$ ). Testing was conducted in a recall format-e.g., "What was the name of the first satellite to be launched?"- and later in a 4-alternative, multiple-choice format-e.g., "Discover, Explorer, Sputnik, or Telstar." All the questions from the 1950s, 1960s, and 1970s had been used in a previous study (Cohen and Squire, 1981). Seven especially difficult questions from the 1970s, which were included in the previous study, were excluded from the present test. The recall test was presented orally, and the recognition test was presented in written form to be completed by the subject.
Famous faces (recall and recognition). The test was an updated version of one originally developed by Albert et al. (1979). Subjects were asked to identify 117 photographs of famous people who came into the news between 1940 and $1985(1940 s, N=24 ; 1950 s, N=27 ; 1960 s, N=$ $27 ; 1970 \mathrm{~s}, N=27 ; 1980 \mathrm{~s}, N=12$ ). In the recall portion of the test, subjects were presented each photograph and asked to identify the person (e.g., Marilyn Monroe). $\Lambda$ fter the recall test was completed, subjects were shown all of the nonrecalled photographs one at a time and given either a yes-no recognition question (e.g. "Is this person's name Marilyn Monroe?" Half of the time, the name that was presented was correct), or a 3-choice multiple-choice question (e.g., "Which of the following is the name of this person? Gwen Verdon, Brigitte Bardot, or Marilyn Monroe"). The recognition score was based on the items that were correctly recalled plus the items that were correctly recognized. The 2 types of questions (yes/no or multiple-choice) were alternated within each decade for all the nonrecalled photographs. In this way, chance performance on the recognition test was $41.5 \%$ (the average of 50 and $33.3 \%$ ). The items from 1940-1979 had been used in a previous study (Cohen and Squire, 1981).

\section{Procedure}

All subjects received both the public events and famous faces tests. The recall section of each test always preceded the recognition section. The public events tests were administered between October 1985 and June 1986. The famous faces tests were administered between April and October 1986

\section{Results}

The data for the public events test were submitted to a $2 \times 4$ repeated-measures analysis of variance, with group and decade as independent variables. The famous faces data were submitted to a $2 \times 5$ repeated-measures analysis of variance, also with group and decade as independent variables. Recall and recognition data for each test were considered separately.

\section{Patients with Korsakoff's syndrome and alcoholic control subjects}

Figure 1 shows the results for the public events and famous faces tests (both recall and recognition), and Figure 2 shows individual scores for the patients. On the recall portion of the public events test, the overall performance of amnesic patients was poorer than that of the control subjects $(F[1,14]=12.7, p<0.01)$. There was also a significant effect of decade $(F[3,42]=17.1, p$ $<0.001)$, and an interaction of group $\times$ decade $(F[3,42]=2.8$, $p=0.05)$. Planned comparisons between groups for each decade indicated that the patients performed worse for the 1980s $(t[14]$ $=3.5, p<0.01)$ and for the $1970 \mathrm{~s}(t[14]=2.9, p<0.05)$. A marginal difference was found for the $1960 \mathrm{~s}(t[14]=2.0, p<$ $0.07)$, and there was no significant difference for the $1950 \mathrm{~s}(t[14]$ $=1.3, p>0.10$ ).

On the recognition portion of the test, the patients also performed more poorly than the control subjects $(F[1,14]=13.9$, $p<0.01)$. There was a significant effect of decade $(F[1,14]=$ $5.4, p<0.01)$ and a significant interaction of group $\times$ decade $(F[3,42]=3.5, p<0.05)$. Planned comparisons within decades demonstrated that the patients performed poorly on questions about the 3 most recent decades: the 1980 s $(t[14]=3.3, p<$ $0.01)$, the $1970 \mathrm{~s}(t[14]=3.2, p<0.01)$, and the $1960 \mathrm{~s}(t[14]=$ $2.7, p<0.05)$. The scores for the 1950 s fell just short of significance $(t[14]=2.0, p<0.06)$.

The results for the famous faces test were similar to the results for public events. On the recall portion, the patients performed overall more poorly than the control subjects $(F[1,14]=6.5$, $p<0.05)$. A significant effect was also obtained for decade $(F[4,56]=7.7, p<0.001)$ and for the interaction of group $\times$ decade $(F[4,56]=5.7, p<0.01)$. Planned comparisons for 


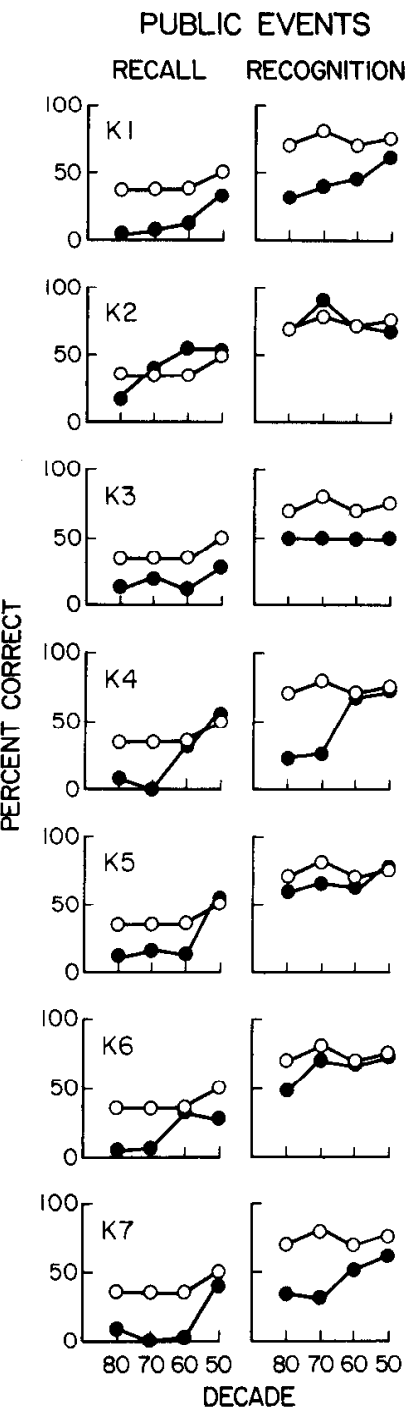

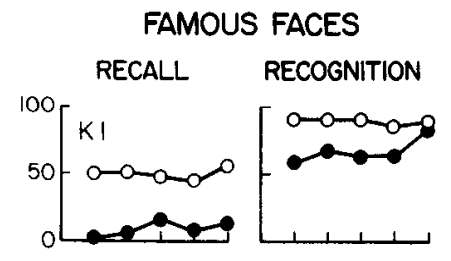
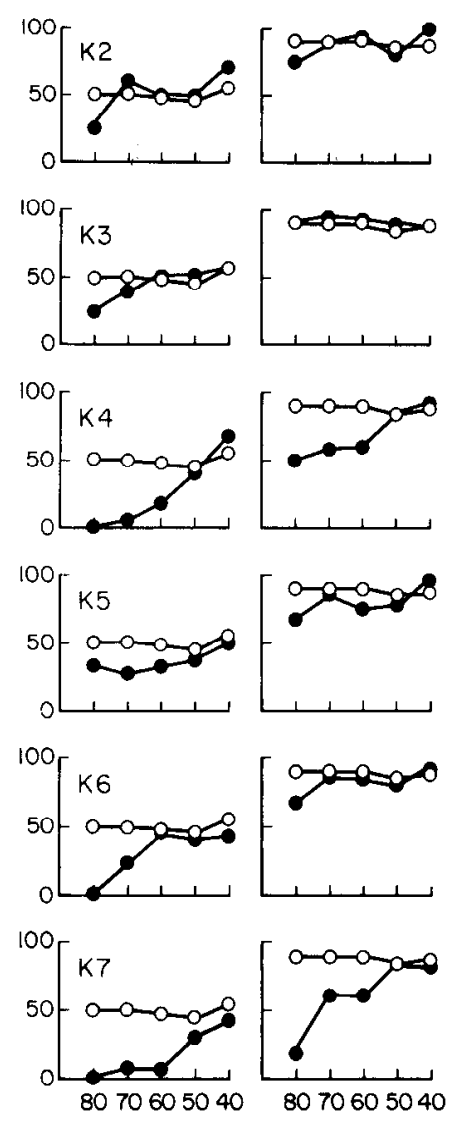

DECADE

Figure 2. Individual scores of the 7 patients with Korsakoff's syndrome (closed circles) on the public events and famous faces tests (recall and recognition). For comparison, the average scores for the alcoholic control subjects $(n=9)$ are shown as open circles in each panel. Chance performance on the recognition tests was $25 \%$ for public events and $41.5 \%$ for famous faces.

each decade showed that the patients scored more poorly than the controls in the 3 most recent decades: the 1980s $(t[14]=$ $3.4, p<0.01)$, the $1970 \mathrm{~s}(t[14]=2.7, p<0.05)$, and the $1960 \mathrm{~s}$ $(t[14]=2.4, p<0.05)$. Scores for the 1950s and 1940s were not significantly impaired $(t \mathrm{~s}[14]<1.2, p \mathrm{~s}>0.10)$.

On the recognition portion of the test, patients also performed more poorly than controls $(F[1,14]=7.2, p<0.05)$. In addition, the effect of decade $(F[4,56]=4.6, p<0.01)$ and the interaction of group $\times$ decade were significant $(F[4,56]=7.6, p<0.001)$. Planned comparisons within each decade showed that the patients scored more poorly than the controls in the 3 most recent decades: the 1980s $(t[14]=3.3, p<0.01)$, the $1970 \mathrm{~s}(t[14]=$ $2.4, p<0.05)$, and the $1960 \mathrm{~s}(t[14]=2.7, p<0.05)$. Scores for the 1950s and the 1940s were not significantly impaired $(t \mathrm{~s}$ $[14]<1.0, p s>0.10$ ).

These findings for patients with Korsakoff's syndrome differed from previous findings obtained for 9 Korsakoff patients (Cohen and Squire, 1981), 4 of whom also served in the current study.

\section{PUBLIC EVENTS}
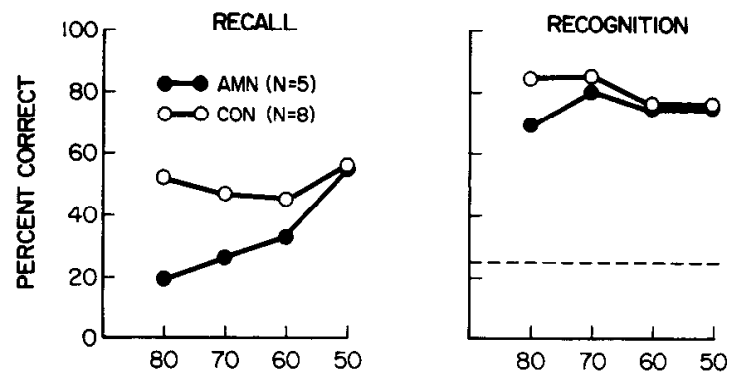

FAMOUS FACES
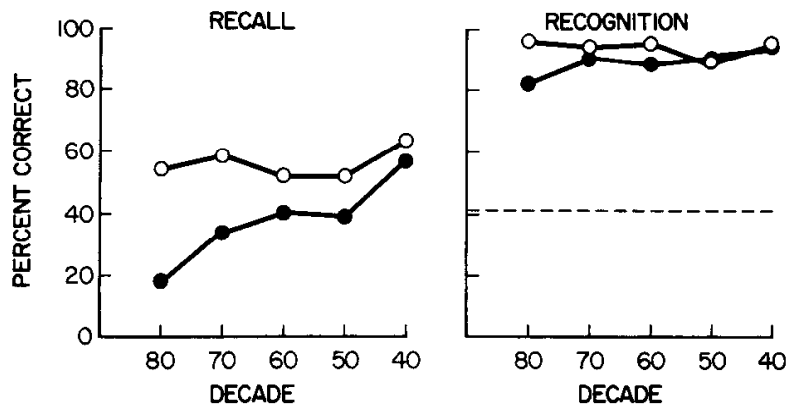

Figure 3. Performance of amnesic patients (non-Korsakoff) with amnesia due to anoxia or ischemia and healthy control subjects on the public events test (recall and recognition) and on the famous faces tcst (recall and recognition). Dashed lines indicate chance performance levels (public events $=25 \%$; famous faces $=41.5 \%$ ).

In the current study, remotc memory scorcs wcre temporally graded. Performance was impaired on items that asked about the most recent decades but reached normal levels on items that asked about the most remote decades. In the previous study, performance was also temporally graded; however, performance was nevertheless impaired across all the time periods covered by the test. This difference in the 2 results was not a simple consequence of the control subjects in the present study having performed more poorly on items about very remote events than the control subjects in the previous study. Indeed, the 2 control groups performed almost identically (e.g., 1950s public events recall: first study, $49 \%$; second study, $48.7 \% ; 1940$ s famous faces recall: first study, 56.6\%; second study, $54.2 \%$ ).

A further comparison of the 2 sets of findings showed that the 4 patients who participated in both studies $(\mathrm{K} 1, \mathrm{~K} 3, \mathrm{~K} 4$, and K5; see Fig. 2 for the individual scores of these 4 patients in the present study) performed about the same on both occasions. We examined performance on those items that were tested in both studies (items for the 1950s, 1960s, and 1970s for public events and items from the 1940s, 1950s, 1960s, and 1970s for famous faces). The average change from the first to the second study was $2.0,8.5$, and $3.5 \%$ for $1950 \mathrm{~s}-1970 \mathrm{~s}$ public events recall; $8.4,5.2$, and $-6.0 \%$ for public events recognition; 0.0 , $0.0,1.0$, and $6.8 \%$ for $1940 \mathrm{~s}-1970 \mathrm{~s}$ famous faces recall; and $1.0,-0.7,1.0$, and $12.7 \%$ for famous faces recognition. None of these differences approached significance ( $p s>0.10$ ).

These comparisons indicate that there must be considerable heterogeneity within the Korsakoff population. Some patients achieve normal scores on items about very remote events (this pattern described the average performance in the present study). 

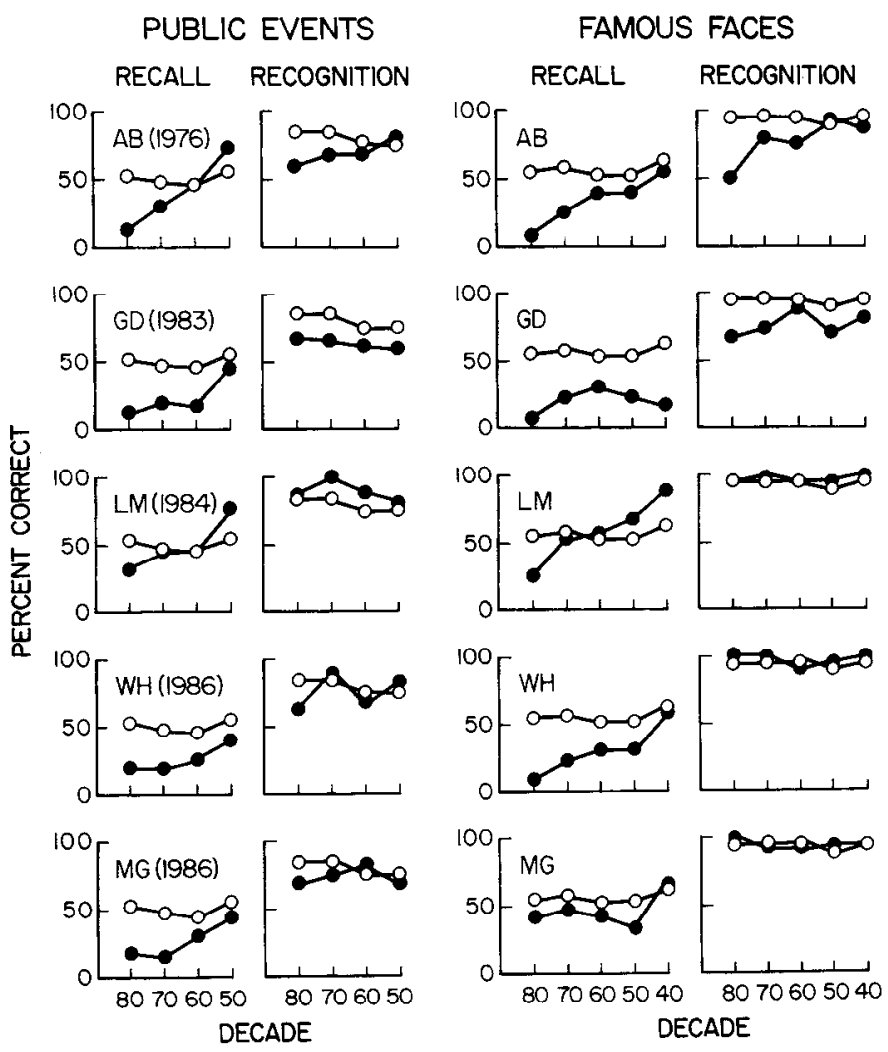

Figure 4. Individual scores of 5 amnesic patients (closed circles) on the public events and famous faces tests (recall and recognition). For comparison, the average scores for the healthy control subjects $(n=8)$ are shown as open circles in each panel. The year when amnesia began is shown in parentheses next to each patient's initials. Chance performance on the recognition tests is $25 \%$ for public events and $41.5 \%$ for famous faces.

Other patients are impaired even on items about very remote events [This pattern described the average performance in the previous study (Cohen and Squire, 1981).]

\section{Amnesic patients (non-Korsakoff) and healthy control subjects}

Figure 3 shows the results for the public events and famous faces tests (both recall and recognition), and Figure 4 shows individual scores for the patients. On the recall portion of the public events test, overall performance was marginally poorer for the patients than the control subjects $(F[1,11]=4.5, p<0.06)$. There was a significant effect of decade $(F[3,33]=12.9, p<0.001)$, as wcll as an interaction of group $\times$ decade $(F[3,33]=7.1, p<$ $0.001)$. Planned comparisons within each decade indicated that the patients performed more poorly than control subjects in the $1980 \mathrm{~s}(t[11]=3.4, p<0.01)$ and the 1970s $(t[11]=2.3, p<$ $0.05)$. Scores from the $1960 \mathrm{~s}$ and the $1950 \mathrm{~s}$ were not significantly different $(t \mathrm{~s}[11]=1.4, p \mathrm{~s}>0.10)$.

On the recognition portion of the public events test, patients and control subjects did not differ overall $(F[1,11]=1.6, p>$ $0.10)$. In addition, no effect was found for decade $(F[3,33]=$ $2.0, p>0.10)$, and there was only a marginal effect of group $\times$ decade $(F[3,33]=2.4, p<0.09)$. Planned comparisons within each decade indicated that patients performed more poorly than control subjects only for the $1980 \mathrm{~s}(t[11]=2.6, p<0.05)$ but performed similarly for the $1970 \mathrm{~s}, 1960 \mathrm{~s}$, and 1950s $(t \mathrm{~s}[11]<$ $0.9, p s>0.10)$.

On the recall portion of the famous faces test, the patients performed worse than the control subjects $(F[1,11]=7.0, p<$ $0.05)$. There was a significant effect of decade $(F[4,44]=9.0$, $p<0.001)$ and a significant interaction of group $\times$ decade $(F[4,44]=4.2, p<0.01)$. Planned comparisons within each decade indicated that the patients scored more poorly for the $1980 \mathrm{~s}(t[11]=4.1, p<0.01)$ and for the $1970 \mathrm{~s}(t[11]=3.0, p$ $<0.05)$. No significant differences were found within the other decades $(t \mathrm{~s}[11]<1.8, p \mathrm{~s}>0.10)$.

On the recognition portion of the famous faces test, no overall difference was found between groups $(F[1,11]=1.7, p>0.10)$. There was no effect of decade $(F[4,44]=1.1, p>0.10)$, but the interaction of group $\times$ decade was significant $(F[4,44]=$ $2.7, p<0.05$ ). Planned comparisons within each decade showed that the patients were significantly impaired only for the $1960 \mathrm{~s}$ $(t[11]=2.4, p<0.05 ;$ for the other decades, $t \mathrm{~s}[11]<1.8, p \mathrm{~s}$ $>0.10)$.

\section{Experiment 2A}

This experiment was carried out in order to evaluate the consistency of remote memory performance by amnesic patients.

\section{Methods}

Subjects

All of the amnesic patients and control subjects described in Experiment 1 were tested.

\section{Materials}

The tests were the same as those given in Experiment 1 (public events and famous faces, recall and recognition).

\section{Procedure}

The tests given in Experiment 1 were administered again on a second occasion approximately a year later. The second administration of the public events tests occurred between March and June 1987. The average interval between the first and second testing was 14.3 months (range, 4-18 months). The famous faces tests were given a second time between March and June, 1987, with an average interval between the first and second testing of 10.6 months (range, 4-14 months).

\section{Results}

The results of the second test administration can be summarized by stating that the scores for all groups were virtually the same as on the first test. Specifically, on the 4 remote memory tests (public events recall, public events recognition, famous faces recall, and famous faces recognition), the overall difference scores for the 2 test occasions (second test minus first test) were as follows: patients with Korsakoff's syndrome, 3.7, 2.9, 2.8, and $5.5 \%$; alcoholic control subjects, $5.1,-0.4,4.1$, and $2.6 \%$; patients with non-Korsakoff amnesia, $0.7,2.1,5.7$, and $0.7 \%$; and healthy control subjects, $3.9,1.0,9.3$, and $1.5 \%$. None of these differences was statistically significant (all $p \mathrm{~s}>0.10$ ).

Further comparisons within each decade revealed no significant differences in performance across testing occasions in either patient group ( $p s>0.10$ ). Alcoholic control subjects did improve on public events recall for the $1960 \mathrm{~s}(t[16]=2.3, p<$ $0.05)$, as well as on famous faces recognition for the 1950s $(t[16]$ $=2.0, p<0.06$; all other comparisons: $t \mathrm{~s}[16]<1.5, p \mathrm{~s}>0.10$ ). Healthy control subjects improved on famous faces recognition for the $1950 \mathrm{~s}(t[14]=2.7, p<0.05)$ and improved marginally on recall of famous faces for the $1970 \mathrm{~s}(t[14]=1.8, p<0.10$; all other comparisons: $t \mathrm{~s}[14]<1.6, p \mathrm{~s}>0.10$ ). Considering that 72 different comparisons were made, and that therefore approximately 4 significant differences would be expected to 
Table 2. Item analysis: performance of amnesic patients and control subjects across 2 testing occasions

\begin{tabular}{|c|c|c|c|c|c|c|c|c|c|c|c|c|}
\hline \multirow[b]{3}{*}{ Group } & \multicolumn{6}{|l|}{ Recall } & \multicolumn{6}{|c|}{ Recognition } \\
\hline & \multicolumn{3}{|c|}{ Consistent } & \multicolumn{3}{|c|}{ Inconsistent } & \multicolumn{3}{|c|}{ Consistent } & \multicolumn{3}{|c|}{ Inconsistent } \\
\hline & $\mathrm{C}-\mathrm{C} \%$ & I-I\% & Sum-1 & $\mathrm{I}-\mathrm{C} \%$ & $\mathrm{C}-\mathrm{I} \%$ & Sum-2 & $\mathrm{C}-\mathrm{C} \%$ & $\mathrm{I}-\mathrm{I} \%$ & Sum-3 & $\mathrm{I}-\mathrm{C} \%$ & C-I\% & Sum-4 \\
\hline \multicolumn{13}{|c|}{ Public events } \\
\hline KOR & 14.9 & 71.9 & 86.8 & 8.4 & 4.8 & 13.2 & 42.2 & 31.7 & 73.9 & 14.3 & 11.8 & 26.1 \\
\hline ALC & 31.3 & 49.9 & 81.2 & 12.3 & 6.5 & 18.8 & 65.4 & 18.5 & 83.9 & 8.2 & 7.9 & 16.1 \\
\hline $\mathrm{AMN}$ & 21.7 & 58.7 & 80.4 & 10.2 & 9.4 & 19.6 & 65.7 & 15.4 & 81.1 & 10.4 & 8.5 & 18.9 \\
\hline $\mathrm{CON}$ & 40.5 & 37.6 & 78.1 & 12.7 & 9.2 & 21.9 & 73.2 & 11.4 & 84.6 & 8.0 & 7.4 & 15.4 \\
\hline \multicolumn{13}{|c|}{ Famous faces } \\
\hline KOR & 26.5 & 59.2 & 85.7 & 8.6 & 5.7 & 14.3 & 71.2 & 9.8 & 81.0 & 12.0 & 6.9 & 19.0 \\
\hline ALC & 44.8 & 42.1 & 86.9 & 8.8 & 4.3 & 13.1 & 85.2 & 5.1 & 90.3 & 6.2 & 3.5 & 9.7 \\
\hline AMN & 32.6 & 49.0 & 81.5 & 11.6 & 6.9 & 18.5 & 83.4 & 4.7 & 88.1 & 5.4 & 6.5 & 11.9 \\
\hline $\mathrm{CON}$ & 51.5 & 31.1 & 82.6 & 13.0 & 4.4 & 17.4 & 90.1 & 2.3 & 92.4 & 4.5 & 3.1 & 7.6 \\
\hline
\end{tabular}

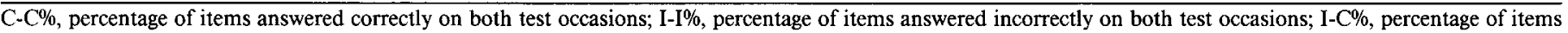

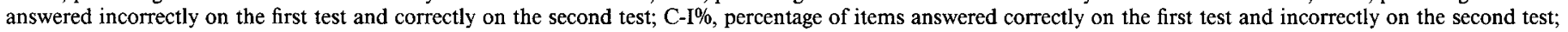
KOR, patients with Korsakoff's syndrome; $\Lambda L C$, alcoholic control subjects; $\Lambda \mathrm{MN}$, other patients with amnesia; CON, healthy control subjects.

occur by chance ( 3 such differences were found), it seems reasonable to suppose that all groups performed similarly across the 2 testing occasions.

While all groups obtained similar scores on the 2 testing occasions, a question remains concerning the extent to which the same items were correct on both occasions. In principle, it would be possible to obtain a similar score on 2 successive test administrations by answering one set of items correctly on the first test and a different set of items correctly on the second test.

To address this question, we compared responses to individual items on the 2 testing occasions. Items were categorized as either correct on both occasions, incorrect on both occasions, correct on the first occasion and incorrect on the second, or incorrect on the first occasion and correct on the second. Table 2 shows the percent of items in each of these four categories for each of the four remote memory tests. The columns labeled Sum-1 through Sum-4 show the percent of items that were treated either consistently (i.e., the items were always correct or incorrect) or inconsistently (i.e., the items were correct on one occasion and incorrect on the other occasion). The finding that it was somewhat more likely for an item to change from incorrect to correct (columns I-C\%) than to change from correct to incorrect (columns C-I\%) is consistent with the overall small improvement in scores that was observed on the second testing (overall improvement across groups and tests was 3.2\%).

The consistency scores in Table 2 were submitted to 2 separate $4 \times 2$ ANOVAs, with the 4 subject groups and the 2 tests (public events and famous faces) as independent factors. Separate analyses were conducted for the recall and recognition test data, i.e., for the scores contributing to the Sum-1 and Sum-3 columns. For the recall tests, there was an effect of group $(F[3,25]=4.6$, $p<0.05)$ and a marginal effect of tests $(F[1,25]=4.0, p<$ $0.07)$. That is, subjects were somewhat more consistent overall on the famous faces test than on the public events test. There was no group $\times$ test interaction $(F[3,25]=1.6, p>0.10)$. Planned comparisons between each patient group and their corresponding control group showed that the patients with Korsakoff's syndrome were marginally more consistent than their control subjects on the public events recall test $(t[14]=2.1, p$ $<0.06)$. None of the other comparisons between groups in the Sum-1 column approached significance $(p s>0.10)$.
For the recognition tests there was an effect of group $(F[3,25]$ $=6.8, p<0.01)$ and an effect of test $(F[1,25]=23.5, p<$ $0.001)$. That is, just as with the recall tests, subjects were more consistent on the famous faces test than on the public events test. There was no group $\times$ test interaction $(F[3,25]<1.0, p$ $>0.10)$. Planned comparisons showed that patients with Korsakoff's syndrome were less consistent than their control subjects on both tests $(t \mathrm{~s}[14]>2.7, p s<0.05)$. None of the other comparisons between groups in the Sum-3 column approached significance $(p s>0.10)$.

In summary, there was some variability in the responses to individual items across the 2 testing occasions. Overall, subjects were more consistent on the famous faces test than on the public events test. Across the 2 testing sessions, the non-Korsakoff amnesic patients were just as consistent on all the tests as their control subjects. Patients with Korsakoff's syndrome were more consistent than their control subjects on the public events recall test and just as consistent on the famous faces recall test. They were less consistent than their control subjects on both recognition tests. Thus, for the amnesic patients, increased inconsistency in responding across the 2 testing occasions was observed only in Korsakoff's syndrome and then only for the recognition tests.

\section{Experiment 2B}

Experiment $2 \mathrm{~A}$ showed that amnesic patients and control subjects performed rather consistently across 2 testing sessions in terms of how the same items were answered on each occasion. Nevertheless, both amnesic patients and control subjects did change their responses (from correct to incorrect or from incorrect to correct) for some of the items on each of the 4 remote memory tests. That is, subjects answered some items correctly on the second test session that they had failed to answer on the first test. Although in the course of taking the test on 2 separate occasions, the control subjects accumulated significantly more correct items than the amnesic patients (55.9 vs. $33.6 \%), t[27]$ $=4.4, p<0.001$ ), it remained possible that the amnesic patients, given a sufficient number of testing opportunities, might eventually catch up with the control subjects and thereby demonstrate that they possessed just as much knowledge about remote 


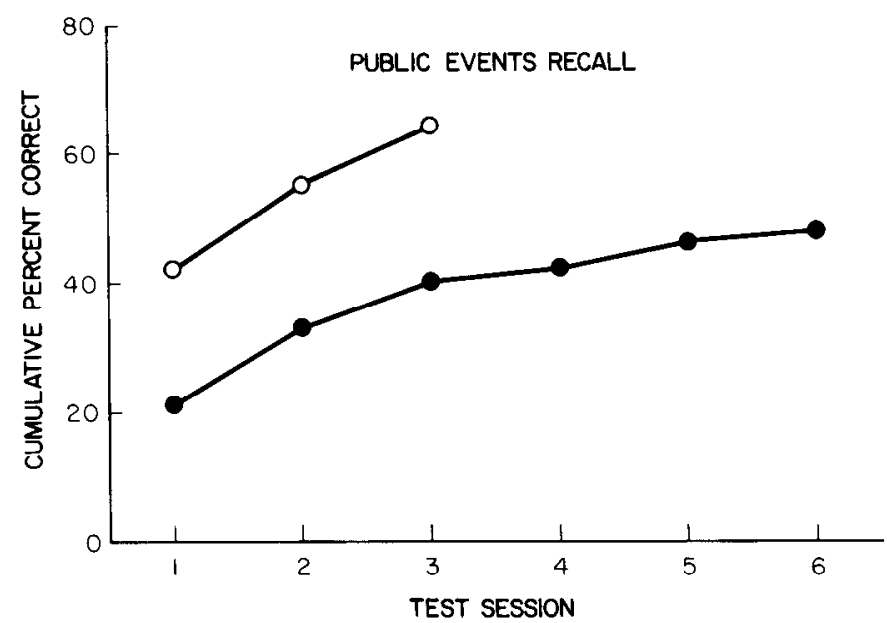

Figure 5. Performance of 4 of the amnesic patients (closed circles) and 4 control subjects (open circles) on the public events recall test across multiple test sessions. The score for each session (cumulative percent correct) reflects the total number of test items answered correctly at least once during that session or a previous one.

events as the control subjects. Experiment $2 \mathrm{~B}$ tested this possibility.

\section{Methods}

\section{Subjects}

Amnesic patients. Four of the patients from Experiments 1 and $2 \mathrm{~A}$ were tested (K4, K5, K6, and MG). These 4 patients were selected because their percent correct score on the first administration of the public events recall test (Experiment 1, 20.9\%) was similar to the average score obtained by all 12 amnesic patients (Experiment 1, 23.4\%).

Control subjects. Three of the alcoholic control subjects and one healthy control subject from Experiments 1 and $2 \mathrm{~A}$ were tested. These 4 subjects were selected because their score on the first administration of the public events recall test (Experiment 1,41.3\%) was similar to the average score obtained by all 17 control subjects (Experiment 1, 43.4\%).

\section{Materials and procedure}

The public events recall test used in Experiments 1 and $2 \mathrm{~A}$ was administered to the amnesic patients 4 additional times in March 1988, approximately 1 year after it had last been given. The 4 testing sessions were scheduled twice each week during a 2 -week period. Upon completion of the final test session, these 4 amnesic patients had received this test a total of 6 times during a $2 \frac{1 / 2}{2}$ ycar pcriod. The 4 control subjects were tested once in March 1988, so that they received this test a total of 3 times during the same $2 \frac{1 / 2}{2}$ year period. The control subjects were not tested further during March 1988 because it seemed likely that they would remember their answers, which would have been given very recently, and would therefore be difficult to compare with the amnesic patients.

\section{Results}

As measured by the percent correct score, performance on the public events recall test did not improve much after the second test administration. The average scores for the 4 amnesic patients across the 6 tests were $20.6,27.7,29.6,30.4,34.5$, and $30.7 \%$. The average scores for the 4 control subjects across 3 tests were $41.8,47.6$, and $56.3 \%$. To determine how much total knowledge amnesic patients were able to demonstrate across the 6 test sessions, we also calculated a cumulative percent correct score for each session. The cumulative score credited an item as correct if it had been answered correctly at least once in any test session. Figure 5 shows the cumulative scores obtained by the 4 amnesic patients and the 4 control subjects.
After 3 test sessions, the control subjects had answered correctly $63.6 \%$ of the test items, whereas after 6 test sessions, the amnesic patients had answered correctly only $43.8 \%$ of the items $(t[6]=2.83, p<0.05)$. The cumulative scores for each subject group were also submitted to 2 separate ANOVAs, with the test sessions and the 4 decades (1950s-1980s) as independent factors. In each case, there was an effect of test session ( $p s<0.001)$, indicating that performance improved; and there was an effect of decade for the amnesic patients $(F[3,12]=15.9, p<0.001)$, indicating that performance was better overall for the more remote decades. However, there was no test session $\times$ decade interaction for either group ( $p s<0.05$ ), indicating that improvement from session to session came equally from all the decades covered by the test.

These results suggest that control subjects simply possessed more knowledge about remote events than the amnesic patients. Both groups were able to recall some information on each testing occasion that had not been recalled previously. However, this phenomenon occurred to about the same extent in both groups. Moreover, the amnesic patients eventually reached a point where little new information could be added in a testing session. Control subjects accumulated significantly more information before they reached this same point.

\section{Experiment 3}

This experiment assessed the ability of amnesic patients to answer general information questions that varied in their level of difficulty.

\section{Methods}

Subjects

Patients with Korsakoff's syndrome. See Experiment 1. The 7 patients averaged 56.3 years of age at the time of testing.

Other patients with amnesia. See Experiment 1 . The 5 patients averaged 54.4 years of age at the time of testing.

Alcoholic control subjects. Ten alcoholic subjects, 7 men and 3 women, were tested and served as a control group for the patients with Korsakoff's syndrome. Seven of these subjects also participated in Experiments 1 and 2. All subjects were current or former participants in alcohol treatment programs in San Diego County. None reported a history of cirrhosis or severe head injury (specifically, a period of unconsciousness lasting longer than $5 \mathrm{~min}$ ). The subjects reported an average drinking history of 16 years (range, 2-33 years) and had abstained from alcohol for an avcragc of 2.1 ycars (rangc, 11-36 months) prior to participating in the study. The subjects averaged 54.6 years of age, had 12.5 years of education, and obtained average WAIS-R subtest scores of 19.3 for Information (18.0 for the patients with Korsakoff's syndrome) and 44.9 for Vocabulary (49.0 for the patients with Korsakoff's syndrome). Immediate and delayed $(12 \mathrm{~min})$ recall of a short prose passage averaged 7.4 and 5.4 segments, respectively.

Healthy control subjects. Eight healthy control subjects, 4 men and 4 women, were tested and served as a control group for the non-Korsakoff patients. Four of these subjects also participated in Experiments 1 and 2. All were employees or volunteers at the San Diego Veterans Administration Medical Center. They averaged 51.4 years of age, had 15.6 years of education, and obtained WAIS-R subtest scores of 22.8 for Information ( 22.0 for the amnesic patients) and 56.4 for Vocabulary (57.8 for the amnesic patients). Immediate and dclaycd (12 $\mathrm{min}$ ) rccall of a short prose passage averaged 8.4 and 7.5 segments, respectively.

\section{Tests}

We compiled a list of 160 general information questions (Nelson and Narens, 1980; Shimamura et al., 1981), all of which asked about information available prior to 1930 [e.g., "What was the last name of the woman who supposedly designed and sewed the first American flag?" [Ross], "What is the last name of the man who was most responsible for photographing the U.S. Civil War?" [Brady]). The questions were 
RECALL

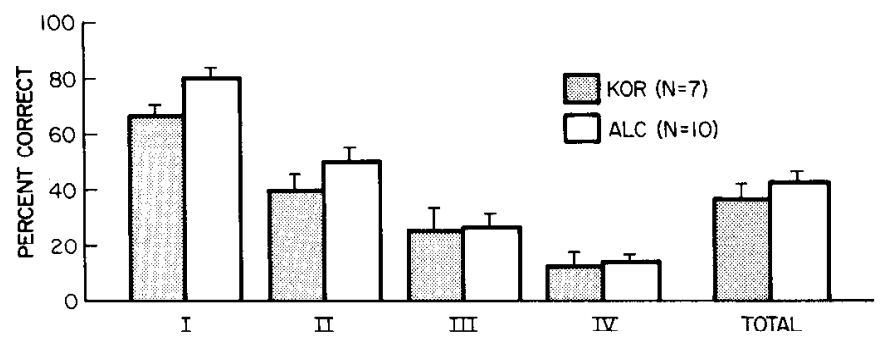

RECOGNITION

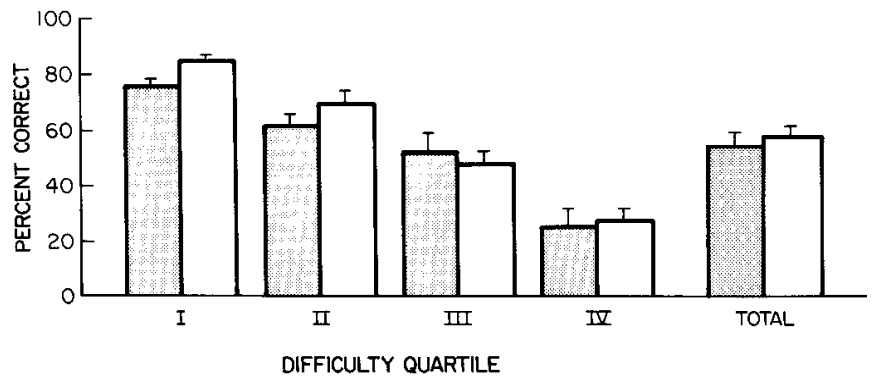

Figure 6. Recall (top) and recognition (bottom) performance for questions about general information. Scores are shown separately for each difficulty quartile $(I-I V)$. The total score on the test is shown to the right. $K O R$, patients with Korsakoff's syndrome; $A L C$, alcoholic control subjects. For the recognition test, chance performance is $12.5 \%$. Brackets show SEM.

rank-ordered based on their difficulty according to normative data for college students provided by Nelson and Narens (1980) and then divided into 4 groups of 40 questions each. The percentage of correctly recalled items in each difficulty quartile based on the published norms was I, $77.8 \%$; II, $47.8 \%$; III, $22.3 \%$; and IV, $5.0 \%$, with an overall average recall score of $38.3 \%$. We also constructed a recognition test for the same 160 questions, using the correct answer together with 7 alternate responses for each item as described by Shimamura et al. (1981). The recall and recognition tests consisted of four 40 -question blocks. Each block contained 10 randomly selected questions from each quartile. The order of the questions was the same for the recall and recognition tests.

\section{Procedure}

The questions were printed individually on $3 \times 5$ index cards. For the recall test, subjects were asked to read each question aloud and attempt to answer it. On the recognition test, subjects also read each question aloud and then chose from 8 alternatives printed on the card below the question. No feedback was provided about the answers. Subjects also rated the confidence of their recognition responses on a 5 -point scale $(1=$ low, $5=$ high). A $5 \times 7$ card of the confidence rating scale, with the end points labeled "pure guess" and "very sure," remained in view for the subject throughout the test. On all but one occasion, the recall test was given in a single session. The recognition test was given in a second session an average of $11 \mathrm{~d}$ after the recall test.

\section{Results}

Figures 6 and 7 show recall and recognition scores for each group as a function of item difficulty. The data for recall and recognition were submitted to separate $2 \times 4$ repeated measures analyses of variance ( 2 groups $\times 4$ difficulty levels). Patients with Korsakoff's syndrome performed overall similarly to control subjects in both recall and recognition $(F[1,15]<1.4$, ps $>0.10)$. There was a strong effect of question difficulty for both tests $(F[3,45]>124.0, p s<0.001)$. The pattern of performance

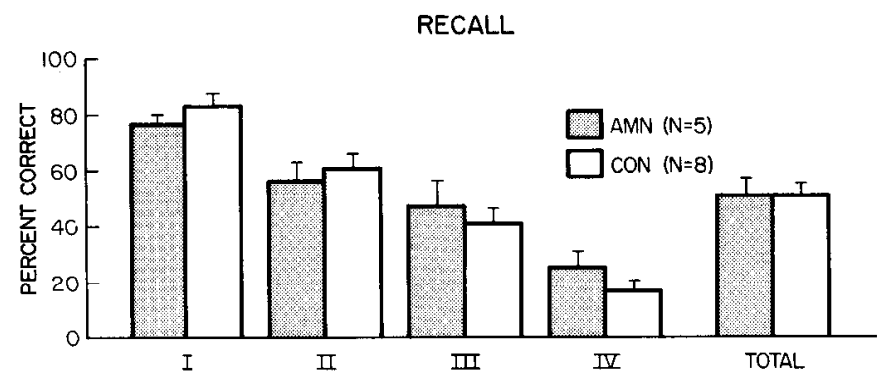

RECOGNITION

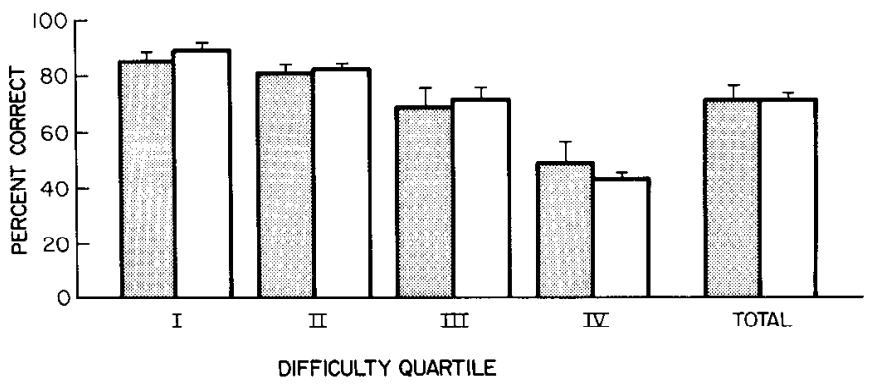

Figure 7. Recall (top) and recognition (bottom) performance for questions about general information. Scores are shown separately for each difficulty quartile $(I-I V)$. The total score on the test is shown to the right. $A M N$, patients with non-Korsakoff amnesia; $H C$, healthy control subjects. For the recognition test, chance performance is $12.5 \%$. Brackets show SEM.

exhibited by the patients with Korsakoff's syndrome and the control subjects tended to differ across difficulty quartiles (group $x$ question difficulty interaction: recall and recognition, $F \mathrm{~s}[3$, $45]=2.4, p \mathrm{~s}<0.09$ ). Planned comparisons between groups within each difficulty quartile indicated that patients with Korsakoff's syndrome answered significantly fewer questions in the easiest quartile for both recall and recognition (quartile $I$, recall and recognition: $t \mathrm{~s}[15]>2.4, p \mathrm{~s}<0.05$; all other comparisons: $\iota \mathrm{s}[15]<1.5, p \mathrm{~s}>0.10)$.

Patients with non-Korsakoff amnesia also performed overall similarly to their control subjects for recall or recognition of general information $(F \mathrm{~s}[1,11]<0.2 p \mathrm{~s}>0.10)$. There was a strong effect of question difficulty for both tests $(F \mathrm{~s}[3,33]>$ $85.0, p \mathrm{~s}<0.001)$. The pattern of performance exhibited by these amnesic patients and their control subjects differed across difficulty quartiles on the recall test (group $\times$ question difficulty interaction: $F[3,33]=3.0, p<0.05$ ) but not on the recognition test (group $\times$ question difficulty interaction: $F[3,33]=1.0, p$ $>0.10$ ). Planned comparisons between groups within each difficulty quartile revealed no significant differences on either the recall or recognition test (all comparisons: $t[11]<1.4, p \mathrm{~s}>$ $0.10)$.

Figure 8 displays confidence ratings separately for each group and for those items that were answered correctly and incorrectly. The data from each patient group were submitted to separate $2 \times 2$ ANOVAs, with group (patients and controls) and type of answer (correct and incorrect) as independent factors. All of the groups were more confident about their correct answers than their incorrect answers (patients with Korsakoff's syndrome and alcoholic control subjects: $F[1,15]=265.6, p<0.001$; patients with non-Korsakoff amnesia and control subjects: $F[1,11]=$ 
Figure 8 . Confidence ratings given by amnesic patients and control subjects for the recognition test of general information ( $1=$ low, $5=$ high). Confdence ratings are shown separately for those questions answered correctly and for those questions answered incorrectly. KOR, patients with Korsakoff's syndrome; $A L C$, alcoholic control subjects; $A M N$, other patients with amnesia; $C O N$, healthy control subjects.
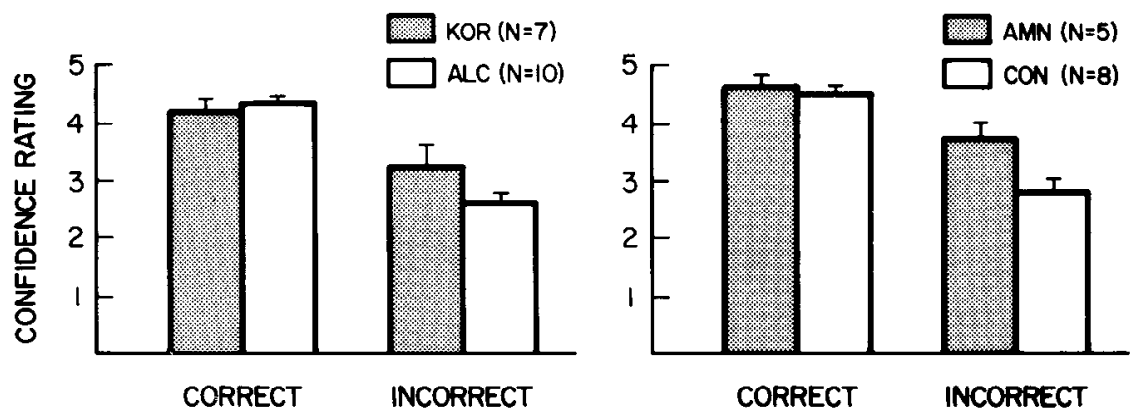

$69.1, p<0.001)$. Overall, the amnesic patients were as confident in their correct answers as control subjects (Korsakoffs vs. alcoholics: $F[1,15]<1.0, p>0.10$ ); non-Korsakoff amnesics vs. controls: $F[1,11]=3.2, p=0.10$ ). However, there was an interaction of group $\times$ confidence ratings (Korsakoffs vs alcoholics: $F[1,15]=14.7, p<0.01$; non-Korsakoffs vs. controls: $F[1,11]=6.9, p<0.05)$. The interaction occurred because amnesic patients had somewhat higher confidence ratings for their incorrect responses than did the control subjects.

In summary, the amnesic patients answered the general information questions as well as the control groups. In addition, there was a tendency for performance to be slightly below control levels for the easier, but not for the more difficult, questions. One explanation for this finding is that the easier material was more likely than the difficult material to be recalled in the years after original learning and therefore more likely to have been rehearsed and relearned. If so, amnesic patients would have been disadvantaged whenever their opportunitics for relcarning occurred in the years immediately preceding or in the years following the onset of amnesia. Confidence ratings for responses in the recognition test were similar across groups, but amnesic patients tended to have more confidence in their incorrect responses than did control subjects.

\section{Discussion}

In the first experiment, retrograde amnesia was observed on average to affect at least the past 15 years (the 1980 s and the 1970s). Although were were large individual differences, the severity and extent of retrograde amnesia were similar for both groups of amnesic patients. Specifically, retrograde amnesia was temporally graded across the most recent time periods and was not detectable in the most remote time periods. In the second experiment, retrograde amnesia was found to be strikingly stable across 2 separate testing sessions separated by a year. An item analysis revealed that subjects in all groups performed rather similarly across the 2 sessions in terms of how many questions were answered in the same way on both tests and how many were answered differently. In particular, across 2 sessions of recall tests the amnesic patients were just as consistent, or more consistent, than the control subjects. Additional testing of a subgroup of these subjects showed that amnesic patients did not catch up to control subjects across multiple test sessions by eventually accumulating as many correct answers as the control subjects. In the third experiment, amnesic patients performed normally on a test of very remote memory for general factual information, even when the questions were very difficult.

In agreement with the present findings, previous studies of remote memory in Korsakoff's syndrome have found memory impairment to be severe and extensive. In most of those studies, as in the present study, performance was better for questions about remote events than for questions about recent events. However, in contrast to the present findings, in previous studies performance did not reach normal levels (Albert et al., 1979; Meudell et al., 1980; Cohen and Squire, 1981). The present study shows that some patients with Korsakoff's syndrome perform normally on questions about very remote events, specifically, events that occurred 30-40 years ago. Thus, the deficit need not extend into the most remote time periods covered by the test. This finding underscores the heterogeneity of the syndrome (see scores for individual patients in Fig. 2). The variability of remote memory performance in Korsakoff's syndrome may not have been appreciated previously because of the convention of presenting averaged data.

One difficulty with studies of retrograde amnesia based on patients with Korsakoff's syndrome is that the time when the memory impairment began can scldom be cstablished unambiguously. As discussed previously, if memory impairment were gradually developing across many years, remote memory impairment in Korsakoff's syndrome might largely reflect anterograde amnesia (Cohen and Squire, 1981; Butters and Albert, 1982; but see Butters and Cermak, 1986). The present study permitted an improved estimate of retrograde amnesia because the 5 non-Korsakoff amnesic patients became amnesic on a known day. The findings for this group show conclusively that extensive loss of memory for premorbid events, i.e., extensive retrograde amnesia, can occur in memory-impaired patients. In the case of the recall tests, retrograde amnesia extended on average about 15 years prior to the onset of amnesia. There was variability within this group of 5 patients (see L.M. vs. W.H. in Fig. 4). Nevertheless, the results show that extensive, temporally graded retrograde amnesia can occur outside of alcoholic Korsakoff's syndrome and in patients whose amnesia is rather well circumscribed. This same point has been made previously in 2 single-case studies (Beatty et al., 1987; Salmon et al., 1988), involving 2 of the 5 non-Korsakoff patients in the present study (LM and WH). These same 5 patients have also been given several tests of autobiographical memory (D. MacKinnon and L. R. Squire, unpublished observations). Retrograde amnesia appeared to be extensive for patients MG, WI, GD, and LM. Recall of memories from childhood and adolescence was intact.

The patients with Korsakoff's syndrome have diencephalic lesions identified by a quantitative CT technique (Shimamura et al., 1988). Available neuropathological data for amnesic patients who sustained an anoxic or ischemic episode suggest that such patients have medial temporal lesions (Cummings et al., 1984; Zola-Morgan et al., 1986). Because the 2 groups in the present study exhibited a strikingly similar form of retrograde 
amnesia, the data provide little basis for making functional distinctions between the diencephalic and medial temporal brain structures that when damaged cause retrograde amnesia. This finding also raises doubts about the view that there are 2 kinds of retrograde amnesia (Cohen and Squire, 1981), one temporally graded and limited to a few years and the other more extensive. The extent of the temporal gradient of retrograde amnesia may simply vary in accordance with the severity of the amnesic condition.

At the same time, extensive ungraded forms of retrograde amnesia have been reported in patients with postencephalitic amnesia (Cermak and O'Connor, 1983; Butters et al., 1984; Damasio et al., 1985), in patients with Alzheimer's disease (Wilson et al., 1981; but see Beatty et al., 1988, and Sagar et al., 1988), in patients with Huntington's disease (Albert et al., 1981) and in one early report involving a mixed group of memoryimpaired patients (Sanders and Warrington, 1971). In these cases, remote memory impairment extended without a temporal gradient across the majority of adult life. Whereas it is possible that this ungraded form of retrograde amnesia is simply the extreme instance on a continuum of severity, it is also possible that extensive, ungraded remote memory impairment is distinct from the temporally graded retrograde amnesias observed here. If so, ungraded, extensive retrograde amnesia may require damage in addition to (or different from) the medial temporal and diencephalic structures that have usually been associaled with memory dysfunction. Moreover, such additional damage might account for some of the heterogeneity that we observed in the extent of temporally graded retrograde amnesia. One finding in support of the latter view comes from the postencephalitic patient Boswell (also known as DRB; Damasio et al., 1985). This patient, who has extensive, severe, and ungraded retrograde amnesia, has radiological evidence of damage to lateral temporal cortex, basal forebrain, and orbital frontal cortex, in addition to medial temporal cortex. Another finding consistent with this view is that the severity of anterograde amnesia and the severity of remote memory impairment are not always correlated (Butters et al., 1984; Shimamura and Squire, 1986). Until there are more patients for whom both neuropsychological and neuroanatomical information are available, it will be difficult to reach firm conclusions about reported variations in the extent of retrograde amnesia and about the relationship between retrograde and anterograde amnesia.

Whatever accounts for variations in the extent and severity of retrograde amnesia, from brief and temporally graded to extensive and temporally graded to extensive and ungraded, it is important to emphasize the variability that occurs, even for the temporally graded retrograde amnesias. Patient R.B., who had a bilateral ischemic lesion limited to the CA1 region of hippocampus (Zola-Morgan et al., 1986), had clinically significant anterograde amnesia but no detectable retrograde amnesia as measured by the same remote memory tests used in the present study. (He may have had a retrograde amnesia limited to the few months or 1-2 years preceding his injury. If so, it would not have been detectable by these tests, which assess memory decade by decade.) By contrast, retrograde amnesia was readily detected in the present group of 5 non-Korsakoff patients (especially GD, WII, and MG). On average, these 5 patients also had a more severe anterograde amnesia than did R.B. The WAIS-WMS difference score for these 5 patients was 28.0 (range, 18-38), and R.B.'s WAIS-WMS difference score was 20 .
These observations lead to a proposal about the neuropathology in the 3 patients of this group with amnesia due to anoxia or ischemia. Because the hippocampus is particularly vulnerable to damage by anoxia or ischemia and was damaged in patient R.B., it seems likely that the pathology in these 3 patients will also prove to include the hippocampus. However, because the anterograde and retrograde amnesia was on average more severe in these patients than in R.B., it seems likely that the pathology will also extend beyond the hippocampus, possibly involving adjacent and anatomically related cortex: subiculum, entorhinal cortex, perirhinal cortex, and parahippocampal gyrus. That is, both anterograde amnesia and temporally graded retrograde amnesia may become more severe as additional damage occurs within the medial temporal region. In studies of nonhuman primates, the memory impairment associated with bilateral lesions of hippocampus is increased by including additional, more rostral structures in the removal (Mishkin, 1978; Squire and Zola-Morgan, 1988).

This proposal about retrograde amnesia seems to be contradicted by the findings from the well-studied patient H.M., who has surgical lesions reportedly involving the entire anterior medial surface of both temporal lobes. H.M. has more severe anterograde amnesia than any of the 5 non-Korsakoff patients studied here but appears to have retrograde amnesia covering only 3-11 years prior to his surgery (Milner et al., 1968; MarslenWilson and Teuber, 1975; Corkin, 1984). Thus, H.M., who became amnesic at the age of 27 , reportedly has retrograde amnesia extending into his teenage years but not into his earlier childhood. One possibility that has scarcely been explored is that early memories tend to be more resistant to amnesia than memories formed later in life. If H.M. had become amnesic in middle age, like most of our study patients, perhaps he would have exhibited more extensive retrograde amnesia.

The present findings also permit some consideration of the nature of remote memory impairment in amnesia. In a previous single-case study, Cermak and O'Connor (1983) reported that a postencephalitic patient (case S.S.) was inconsistent in his remote memory performance across 2 testing sessions. Specifically, on the second test he answered correctly 19 of the 85 public events test items that he had answered incorrectly on the first recall test. Although the consistency of control subjects was not assessed, this finding raised the possibility that a great many of the test items were potentially available for recall. In the limiting case, an amnesic patient might accumulate across several testing sessions as many correct answers as normal subjects. If so, retrograde amnesia should be described as a deficit in accessing memories that are both stored and potentially retrievable.

Experiment 2 showed that, whereas amnesic patients did exhibit some inconsistency across testing sessions, the tendency to switch from incorrect to correct responses occurred at about the same rate in normal subjects. Indeed, this tendency was not markedly different from what was previously reported for patient S.S. He switched from incorrect to correct answers for $14 \%$ of the public events questions and for $23 \%$ of the famous faces (compare to Table 2: healthy control subjects switched from incorrect to correct answers for $13 \%$ of the public events items and for $13 \%$ of the famous faces). These comparisons suggest that amnesic patients and control subjects have a similar tendency to vary their responses across sessions but that amnesic patients simply have less total information available than control subjects. This idea was confirmed in Experiment 2B, where 
it was found that amnesic patients did not reach normal levels of performance even when given an opportunity to accumulate correct answers across 6 test sessions. Thus, there was no hint that the amnesic patients had an impaired access to memories, compared with normal subjects, that they could overcome across multiple testing sessions. On the contrary, the results are consistent with the proposal that control subjects simply possess more knowledge about remote events than amnesic patients. Across multiple testing sessions, both groups could improve their scores to some extent by accumulating more correct answers, but control subjects maintained their advantage over amnesic patients.

One difficulty that complicates the study of retrograde amnesia is that the available tests for assessing remote memory are quitc impcrfect. As discusscd previously (Squirc, 1974; Squirc and Cohen, 1982), it is difficult with most tests to compare results across different time periods. In the case of the tests of past public events and famous faces used here, scores of normal subjects are typically similar across decades. However, there is no assurance that the items tested in different decades are actually equivalent, i.e., that the material tested in different time periods was learned originally to a similar degree and then forgotten at a similar rate. Accordingly, the interpretation of temporal gradients of retrograde amnesia derived from these tests remains somewhat uncertain. One possibility is that remote memories appear to be spared in amnesia because the test material used to assess remote events was better learned originally than the material used to assess recent events. Albert et al. (1979) addressed this issue by analyzing separately the responses to difficult and easy items on a remote memory test. Experiment 3 of the present study addressed this issue by asking extremely difficult questions about very remote events. Because amnesic patients performed normally on the difficult questions, it seems likely that very remote memory, at least for general factual information, can be entirely intact in amnesia. Moreover, because factual information is susceptible to retrograde amnesia when it is first acquired (Experiment 1; also see Shimamura and Squire, 1986), those remote memories that survive must be different in some way from recent memories, such that the remote memories are protected from retrograde amnesia.

This difference has previously been considered a kind of consolidation or reorganization process, which begins after learning is completed and which occurs gradually as time passes (Burnham, 1903; McGaugh and Herz, 1972; Squire et al., 1984). During this period-as a result of rehearsal, the learning of related material, or endogenous neural processes - material in memory is strengthened or re-represented. Thus, acquired information is initially dependent on the structures damaged in amnesia, either because these structures maintain the integrity of stored information, or permit retrieval, or both. In time, information becomes independent of the structures damaged in amnesia (also see Squire et al., 1989). The present results suggest that this period of transition lasts for a decade or more. Thus, structures damaged in amnesia remain essential for the recall of stored information for a long time after learning.

These conclusions about retrograde amnesia apply only to stored information of a rather general kind about famous events, people, and other kinds of factual material. It seems clear that such information, so-called semantic knowledge (Tulving, 1983), is quite vulnerable to amnesia when it is first acquired and quite invulnerable when it is old. Further work is needed to evaluate proposals that autobiographical memory about specific times and places, so-called episodic knowledge (Tulving, 1983), is especially susceptible to retrograde amnesia (Cermak, 1984; Kinsbourne, 1987; Tulving et al., 1988; Warrington and McCarthy, 1988).

\section{References}

Albert, M. A., N. Butters, and J. A. Levin (1979) Temporal gradients in the retrograde amnesia of patients with alcoholic Korsakoff's disease. Arch. Neurol. 36: 211-216.

Albert, M. S., N. Butters, and J. Brandt (1981) Patterns of remote memory in amnesic and demented patients. Arch. Neurol. 38: 495500.

Baddeley, A. (1982) Implications of neuropsychological evidence for theories of normal memory. Phil. Trans. R. Soc. London 298: 5972.

Beatty, W. W., D. P. Salmon, N. Bernstein, and N. Butters (1987) Remote memory in a patient with amnesia due to hypoxia. Psychol. Med. 17: 657-665.

Beatty, W. M., D. P. Salmon, N. Butters, W. C. Heindel, and G. A. Granholm (1988) Retrograde amnesia in patients with Alzheimer's disease or Huntington's disease. Neurobiol. Aging 9: 181-186.

Burnham, W. H. (1903) Retroactive amnesia: Illustrative cases and a tentative explanation. Am. J. Psychol. 14: 382-396.

Butters, N., and M. S. Albert (1982) Processes underlying failures to recall remote events. In Human Memory and Amnesia, L. S. Cermak, ed., pp. 257-274, Erlbaum, Hillsdale, NJ.

Butters, N., and L. S. Cermak (1986) A case study of the forgetting of autobiographical knowledge: Implications for the study of retrograde amnesia. In Autobiographical Memory, D. Rubin, ed., pp. 253272, Cambridge University Press, New York.

Butters, N., P. Milliotis, M. S. Albert, and D. S. Sax (1984) Memory assessment: Evidence of the heterogeneity of amnesic symptoms. Adv, Clin. Neuropsychol. 1: 127-159.

Butters, N., D. P. Salmon, C. M. Cullum, P. Cairns, A. I. Troster, D. Jacobs, M. Moss, and L. S. Cermak (1988) Differentiation of amnesic and demented patients with the Wechsler Memory Scale-Revised. Clin. Neuropsychol. 2: 133-148.

Cermak, L. S. (1982) Human Memory and Amnesia, Erlbaum, Hillsdale, NJ.

Cermak, L. S. (1984) The episodic-semantic distinction in amnesia. In Neuropsychology of Memory, L. R. Squire and N. Butters, eds., pp. 55-62, Guilford, New York.

Cermak, L. S., and M. O'Connor (1983) The anterograde and retrograde retrieval ability of a patient with amnesia due to encephalitis. Neuropsychologia 21: 213-224.

Cohen, N. J., and L. R. Squire (1981) Retrograde amnesia and remote memory impairment. Neuropsychologia 19:337-356.

Corkin, S. (1984) Lasting consequences of bilateral medial temporal lobectomy: Clinical course and experimental findings in H. M. Seminars Neurol. 4: 249-259.

Cummings, J. L., U. Tomiyasu, S. Read, and D. F. Benson (1984) Amnesia with hippocampal lesions after cardiopulmonary arrest. Neurology 34: 679-681.

Damasio, A. R., P. J. Eslinger, H. Damasio, G. W. Van Hoesen, and S. Cornell (1985) Multiple amnesic syndrome following bilateral temporal and basal forebrain damage. Arch. Neurol. 42: 252-259.

Hirst, W. (1982) The amnesic syndrome: Descriptions and explanations. Psychol. Bull. 91: 435-460.

Kinsbourne, M. (1987) Brain mechanisms and memory. Hum. Neurobiol. 6: 81-92.

Lezak, M. (1983) Neuropsychological Assessment, 2nd ed., Oxford University Press, New York.

Marslen-Wilson, W. D., and H.-L. Teuber (1975) Memory for remote events in anterograde amnesia: Recognition of public figures from news photographs. Neuropsychologia 13: 347-352.

Mattis, S. (1976) Dementia rating scale. In Geriatric Psychiatry, R. Bellack and R. Karasu, eds., pp. 77-121, Grune \& Stratton, New York.

McGaugh, J. L., and M. J. Herz (1972) Memory Consolidation, Albion, San Francisco. 
Meudell, P. R., B. Northern, J. S. Snowden, and D. Neary (1980) Longterm memory for famous voices in amnesia and normal subjects. Neuropsychologia 18: 133-139.

Milner, B., S. Corkin, and H.-L. Teuber (1968) Further analysis of the hippocampal amnesic syndrome: 14 year follow-up study of $\mathrm{H}$. M. Neuropsychologia 6: 215-234.

Mishkin, M. (1978) Memory in monkeys severely impaired by combined but not by separate removal of amygdala and hippocampus. Nature 273: 297-298.

Nelson, T. O., and L. Narens (1980) Norms of 300 general-information questions: Accuracy of recall, latency of recall, and feeling-of-knowing ratings. J. Verbal Learn. Verbal Bchav. 19: 338-368.

Osterrieth, P. A. (1944) Le test de copie d'une figure complexe [The test of copying a complex figure]. Arch. Psychol. 30: 206-356.

Rey, A. (1964) L'examen clinique en psychologie [The clinical exam in psychology], Presses Universitaires de France, Paris.

Sagar, H., N. J. Cohen, E. V. Sullivan, S. Corkin, and J. H. Growdon (1988) Remote memory function in Alzheimer's disease and Parkinson's disease. Brain 111: 185-206.

Salmon, D. P., B. R. Lasker, N. Butters, and W. W. Beatty (1988) Remote memory in a patient with circumscribed amnesia. Brain Cognition $7: 201-211$

Sanders, H. I., and E. K. Warrington (1971) Memory for remote events in amnesic patients. Brain 94: 661-668.

Schacter, D. L. (1985) Multiple forms of memory in humans and animals. In Memory Systems of the Brain: Animal and Human Cognitive Processes, N. Weinberger, J. McGaugh, and G. Lynch, eds., pp. 351-379, Guilford, New York.

Shimamura, A. P., and L. R. Squire (1986) Korsakofrs syndrome: A study of the relation between anterograde amnesia and remote memory impairment. Behav. Neurosci. 100: 165-170.

Shimamura, A. P., R. F. Landwher, and T. O. Nelson (1981) FACTRIEVAL: A program for assessing someone's recall of general-information facts, feeling-of-knowing judgements for nonrecalled facts, and recognition of nonrecalled facts. Behav. Res. Methods Instrum. 13: 691-692.

Shimamura, A. P., T. Jernigan, and L. R. Squire (1988) Korsakoff's syndrome; radiological (CT) findings and neuropsychological correlates. J. Neurosci. 8: 4400-4410.
Squire, L. R. (1974) Remote memory as affected by aging. Neuropsychologia 12: 429-435.

Squire, L. R. (1986) Mechanisms of memory. Science 232: 1612-1619.

Squire, L. R., and N. J. Cohen (1982) Remote memory, retrograde amnesia, and the neuropsychology of memory. In Human Memory and Amnesia, L. Cermak, ed., pp. 275-303, Erlbaum, Hillsdale, NJ.

Squire, L. R., and A. P. Shimamura (1986) Characterizing amnesic patients for neurobehavioral study. Behav. Neurosci. 100: 866-877.

Squire, L. R., and S. Zola-Morgan (1988) Memory: Brain systems and behavior. Trends Neurosci. 11: 1970-1975.

Squire, L. R., P. C. Slater, and P. M. Chace (1975) Retrograde amnesia: Temporal gradient in very long-term memory following clectroconvulsive therapy. Science 187:77-79.

Squire, L. R., N. J. Cohen, and L. Nadel (1984) The medial temporal region and memory consolidation: A new hypothesis. In Memory Consolidation, H. Weingartner and E. Parker, eds., pp. 185-210, Erlbaum, Hillsdale, NJ.

Squire, L. R., A. P. Shimamura, and D. G. Amaral (1989) Memory and the hippocampus. In Neural Models of Plasticity, J. Byrne and W. Berry, eds., Academic, New York (in press).

Tulving, E. (1983) Elements of Episodic Memory, Clarendon, Oxford, UK.

Tulving, E., D. L. Schacter, D. McLachlan, and M. Moscovitch (1988) Priming of semantic autobiographical knowledge: A case study of retrograde amnesia. Brain and Cognition 8: 3-20.

Warrington, E. K., and R. A. McCarthy (1988) The fractionation of retrograde amnesia. Brain and Cognition 7: 184-200.

Wechsler, D. (1987) Wechsler Memory Scale-Revised, Psychological Corporation, New York.

Weiskrantz, L. (1987) Neuroanatomy of memory and amnesia: A case for multiple memory systems. Hum. Neurobiol. 6: 93-105.

Wilson, R. S., A. W. Kaszniak, and J. H. Fox (1981) Remote memory in senile dementia. Cortex 17:41-48.

Zola-Morgan, S., L. R. Squire, and D. G. Amaral (1986) Human amnesia and the medial temporal region: Enduring memory impairment following a bilateral lesion limited to field CA1 of the hippocampus. I. Neurosci. 6: 2950-2967. 